\title{
Adverse Event Resolution Date
}

National Cancer Institute

\section{Source}

National Cancer Institute. Adverse Event Resolution Date. NCI Thesaurus. Code C93718.

The date (and time) when the adverse event ends or returns to baseline. 